\title{
Effect of ethephon stimulation on natural rubber latex properties; new insight into ethephon stimulation
}

\author{
A.P. Attanayake ${ }^{1 *}$, L. Karunanayake ${ }^{2}$ and A.H.R.L. Nilmini ${ }^{1}$ \\ ${ }^{1}$ Rubber Research Institute of Sri Lanka, Ratmalana. \\ ${ }^{2}$ Department of Chemistry, Faculty of Applied Sciences, University of Sri Jayewardenepura, Gangodawila, Nugegoda.
}

\begin{abstract}
Stimulation based low intensity harvesting (LIH) systems are accepted all over the world as an agronomic tool to overcome issues such as high cost of production, worker scarcity and low economic lifespan of trees in rubber plantation industries. When developing a protocol for ethephon stimulation, yield levels were concerned regardless of the effect on associated latex quality parameters. Therefore, this study elucidated the effect of ethephon on dry rubber yield and associated latex quality parameters together with latex rheological behaviour and physiological parameters. Five stimulation levels of ethephon $(1-5 \%)$ were investigated with RRIC 121 genotype under S/2 d3 (tapping half of the spiral once in three days frequency) harvesting system with unstimulated latex as the control. The results revealed that all the properties studied were significantly affected by the ethephon concentration and maximum yield with optimum properties could be achieved with the application of $3 \%$ ethephon under $\mathrm{S} / 2 \mathrm{~d} 3$ harvesting system.
\end{abstract}

Keywords: Ethephon concentration, Hevea brasiliensis, latex quality, stimulation.

\section{INTRODUCTION}

Stimulation based low intensity harvesting (LIH) systems are widely accepted by rubber growers all over the world to overcome issues such as high cost of production, shortage of skilled harvesters and low economic lifespan in rubber plantations (Vijayakumar et al., 2001; Rodrigo et al., 2012). To overcome the yield loss due to lowering the intensity of harvesting, ethephon stimulation is used as an excellent strategy to obtain desirable yield by removing certain factors, which limit latex flow as well as latex regeneration. Stimulation is not to obtain high yields but to attain a yield more or less equal to the potential yield without any baneful secondary effects (Gener \& du Plessix, 1976). However, the application of recommended dosages of stimulant is of utmost importance and great care should be taken to avoid any over exploitation through stimulation with higher dose and application frequency. Ethephon directly affects the latex regeneration capacity (D’Auzac \& Jacob, 1989) and may also affect latex physico-chemical parameters such as total solids content (TSC), dry rubber content (DRC), volatile fatty acid content (VFA), viscosity and $\mathrm{Mg}^{2+}$ concentration (Attanayake, 2016). Combined effect of ethephon on latex yield, quality and associated physiological properties with different ethephon concentrations have not been studied previously. This paper reports the findings of an investigation on the effect of different concentrations of ethephon on latex physiological and rheological behaviour, and quality of Hevea latex.

\section{METHODOLOGY}

\section{Experimental design and location of the study}

Experiments were laid out in randomised complete block design with 6 treatments and 3 replications under $1 / 2 \mathrm{~S}$ d3 tapping system at the Gallewatta Division of the Rubber Research Institute of Sri Lanka. Each treatment

*Corresponding author (anusha_rrisl@yahoo.com; (D https://orcid.org/0000-0002-5769-1282) 
plot includes 75 healthy trees and each plot was stimulated once in 3 months with $1.6 \mathrm{~g}$ of 1, 2, 3, 4 and $5 \%$ ethephon. One block without stimulation was the control. All the experimental blocks were tapped by the same tapper in order to avoid tapper variability. Samples were collected for 10 consecutive days after stimulation and unless otherwise mentioned, the data represent means and standard deviation of pooled samples for each treatment. Latex physiological analyses were done only with freshly tapped latex samples that were combined for each treatment, which were immersed in ice and sent to the laboratory immediately without preservation for the analysis of sucrose and thiol content. Rest of the latex was preserved with $0.6 \%$ ammonia and sent to the laboratory for the analysis of latex quality parameters.

The data represent the means and standard deviation of samples collected up to 10 tapping days after ethephon stimulation. Data were analysed using Minitab 16 statistical software and one-way ANOVA was performed for mean values of each ethephon concentrations and related quality parameters together with mean separation by using Tukey method. The least significant difference between two treatments was computed at $\mathrm{p}<0.05$.

\section{Measurements}

Analysis of thiol content was carried out by using colourimetric method using a Jenway 6405 UV/Vis spectrophotometer (Boyne \& Ellman, 1972). The amount of thiol was estimated against a standard curve prepared using reduced glutathione.

Analysis of sucrose content was carried out by using colourimetric method (Scott \& Melvin, 1953). Latex yield was calculated as grams per tree per tap using average daily yield and number of trees tapped.
Analysis of dry rubber content and total solids content were carried out according to ISO 126:2005 and ISO 124:2014 standards, respectively. Volatile fatty acid number was determined according to ISO 506:1992. Viscosity of raw latex was determined according to ISO 1652:2011 using Brookfield dial reading viscometer (Model LVT) at $27 \pm 2{ }^{\circ} \mathrm{C}$. The particle sizes of latex were determined by using Fritsch particle size analyser. The measuring range of the instrument was 0.31 $300.74 \mu \mathrm{m}$.

Serum magnesium content was determined by the standard RRISL method. One gram of the latex sample (w) was diluted with $100 \mathrm{~mL}$ distilled water and $10 \mathrm{~mL}$ of pH 10 buffer solution $\left(\mathrm{NH}_{4} \mathrm{Cl}: \mathrm{NH}_{4} \mathrm{OH}: \mathrm{H}_{2} \mathrm{O}\right)$ and $4 \mathrm{~mL}$ of $\mathrm{KCN}$ solution were added to diluted field latex sample. It was titrated with $0.01 \mathrm{M}$ EDTA solution (m) until the colour changed from purple to blue. The determination was carried out in duplicate. Magnesium content was calculated using the following equation; where $\mathrm{m}=$ molarity of EDTA solution $\left(\right.$ moldm $\left.^{-3}\right), \mathrm{V}=$ volume of EDTA $\left(\mathrm{dm}^{3}\right)$ solution and $\mathrm{w}=$ weight of latex sample $(\mathrm{g})$.

$\mathrm{Mg}$ content $(\mathrm{ppm})=\underline{24.312 \times \mathrm{m} \times \mathrm{V} \times 1000}$

$\mathrm{W}$

\section{RESULTS AND DISCUSSION}

\section{Latex physiological parameters}

Latex physiological parameters are influenced by latex metabolism as well as latex flow properties (Do Kim, 1996). With the application of ethephon, thiol content was significantly changed $(p<0.001)$ over a maximum value with the level of stimulation applied. In unstimulated latex, the thiol content was about $0.67 \mathrm{mM}$. It reached

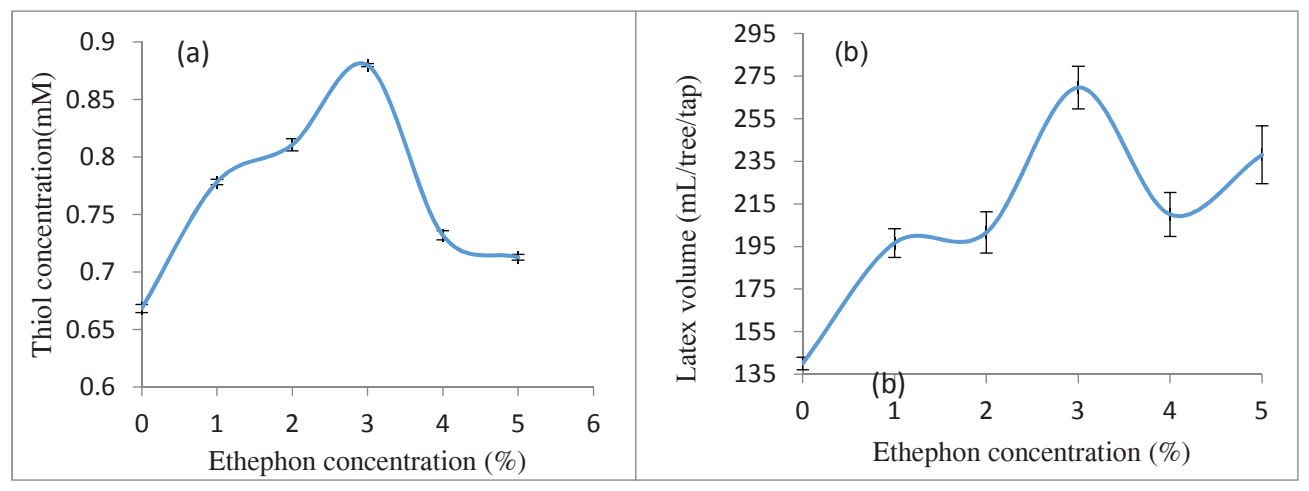

Figure 1: Variation of (a) serum thiol content and (b) latex volume in latex of RRIC 121 genotype harvested under $\mathrm{S} / 2 \mathrm{~d} 3$ system with different ethephon concentrations 
a maximum value of $0.88 \mathrm{mM}$ with $3 \%$ ethephon and reduced to $0.7 \mathrm{mM}$ without any significant variation with further increase (Figure 1a).

It has been reported that TSC, DRC and thiols might have a dual role in latex metabolism and latex flow properties (Jacob et al., 1986). Thiols are the main reducing molecules in latex, which represent the antioxidant activity. Reduction of thiol content below $3 \%$ may be due to enhanced in vitro synthesis of reactive oxygen species (ROS). The free toxic oxygen radicals are oxidised by the thiol groups, which will enhance the latex stability and duration of latex flow time (Do Kim et al., 1996). Thiols act as a potential activator for key enzymes such as invertase and pyruvate kinase (Jacob et al., 1981).

In unstimulated trees, average latex sucrose content was $55.49 \mathrm{mM}$ and with the application of ethephon, latex sucrose content tended to decrease gradually reaching the lowest value of $13.27 \mathrm{mM}$ with $3 \%$ ethephon and gradually increased afterwards reaching up to $25.96 \mathrm{mM}$ with $5 \%$ ethephon (Figure 2).

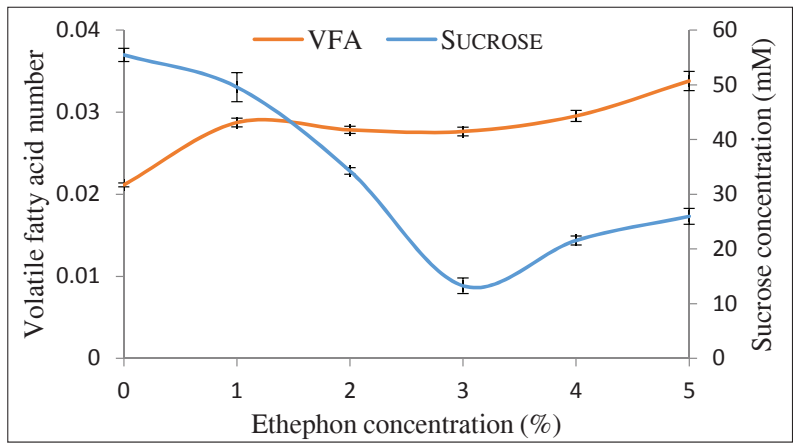

Figure 2: Variation of serum sucrose content and volatile fatty acid content in latex of RRIC 121 genotype harvested under $\mathrm{S} / 2 \mathrm{~d} 3$ system with different ethephon concentration

The efficiency of sucrose conversion to rubber depends on many factors such as clone, season and system of tapping. Sucrose provides metabolic energy for rubber biosynthesis. Yield response to ethephon greatly depends on sucrose availability in latex vessels determining the possibilities for an enhancement of invertase activity after treatment (Tupy, 1973). The reduction of sucrose content up to $3 \%$ might be due to the higher metabolic utilisation of sucrose for rubber production and diminished entry of sucrose from the surrounding cells into latex vessels
(Bealing \& Chua, 1972). It has been reported that higher sucrose consumption is compensated by increased migration of sugar to the treated bark zone by the sink effect of stimulating substances, and higher doses did not improve the production but resulted in a greater sucrose depression in latex (Tupy, 1973). Sucrose deficit could be expected due to exhaustion of the carbohydrate reserves in the tapping panel. However in the present study, further increase of ethephon dosage beyond $3 \%$ caused serum sucrose concentration to gradually increase with simultaneous reduction in rubber yield. Therefore, deficiency in sucrose concentration might occur if the plants are regularly stimulated for several years with high ethephon doses.

\section{Latex yield parameters}

Unstimulated trees gave the lowest latex volume with an average dry rubber content of $43 \%$ resulting in 84 $\mathrm{g}$ of daily dry rubber yield per tree. The volume of latex increased by $7 \%$ with the application of $1 \%$ ethephon and no significant increase in volume was observed up to $2 \%$ ethephon concentration (Figure 1b). Dry rubber content of latex did not significantly vary up to $2 \%$ ethephon concentration. At $3 \%$ ethephon concentration latex volume increased to $270 \mathrm{~mL}$ per tapping, whilst DRC of latex reduced to $37 \%$. When increasing the strength of stimulant further, the volume of latex reduced to $210 \mathrm{~mL}$ per tapping and DRC increased to the value near to $0-2 \%$ ethephon application (Figure 3 ). The maximum latex volume resulted at $3 \%$ ethephon concentration and the volume reduced with the application of higher doses. This might be due to maximum discharge of latex, which does not allow the tree to regenerate cell material in the drainage area when stimulant dosage is very high.

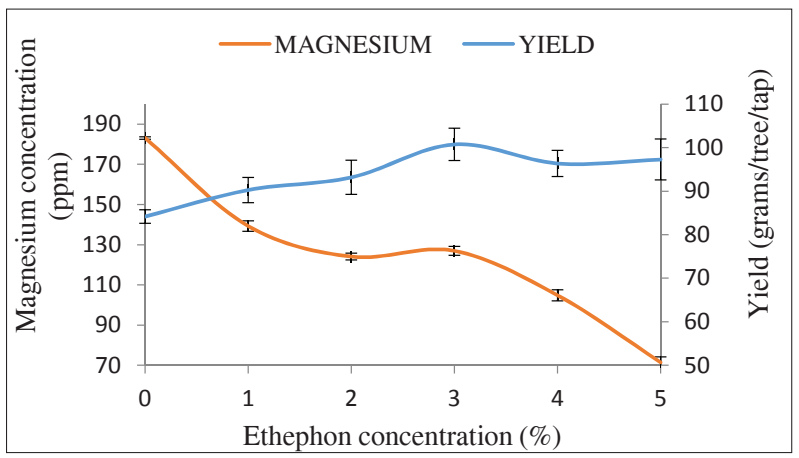

Figure 3: Variation of serum magnesium concentration and dry rubber yield in latex of RRIC 121 genotype harvested under $\mathrm{S} / 2 \mathrm{~d} 3$ system 
Rubber yield of a particular clone in commercial latex production is probably determined not only by the ethephon dosage controlling the biosynthesis of rubber, but also by physiological and biochemical processes controlling latex flow, capacity of the tree to resynthesise latex and other organic constituents within the drained area (Pakianthan, 1977). Daily dry rubber yield of trees without the application of ethephon was about $84 \mathrm{~g}$ and this was remarkably increased by $20 \%$ with the application of $3 \%$ ethephon $\left(100.73 \mathrm{gt}^{-1} \mathrm{t}^{-1}\right)$. Further increase of strength of ethephon negatively affected the dry rubber yield, resulting in $4 \%$ decrease over the yield received with $3 \%$ ethephon (Figure 3 ). It is evident from the above observations that application of higher doses of stimulant would not be effective unless the tapping frequency is reduced beyond once in three days. There should be a sufficient time period to regenerate cell materials lost during tapping.

\section{Latex quality parameters}

\section{Total solid content, dry rubber content and non-rubber content}

Both TSC and DRC values of stimulated samples were significantly reduced with the application of higher concentrations of ethephon above $3 \%$ (p $<0.001)$. DRC and TSC of un stimulated trees were 43 and $46 \%$, respectively. With the application of $1 \%$ ethephon, both DRC and TSC values were reduced by about $16 \%$ and did not vary considerably from $2-4 \%$. However at $5 \%$ level, both TSC and DRC values were significantly reduced to 34.6 and $31 \%$, respectively (Figure 4).

With the gradual increase of ethephon concentration, the difference between total solid content and dry rubber content was significantly increased $(\mathrm{p}<0.05)$, which indirectly indicates the non-rubber content in latex (Figure 4). In unstimulated latex, the average total nonrubber content was $3 \%$ and there was no remarkable variation up to $3 \%$ level. However, further increase of ethephon dosage has significantly increased the total non-rubber content by $26 \%$.

It has been reported that TSC and DRC in stimulated latex were lower than those of the unstimulated latex (Do Kim et al., 1996) and those parameters have an effect on latex viscosity (Van Gills, 1951). Therefore, the findings of this study are in conformity with previous studies. The fall in TSC and DRC values considerably accentuated during the $2^{\text {nd }}$ or $3^{\text {rd }}$ subsequent tapping and accounts for the process of increased production (Jacob et al., 1989). The reduction of TSC plays a significant role in stimulation, which results from increased transmembrane water exchange and partly accountable for increased ease of flow observed after treatment (de Jonge, 1955). Increase in non-rubber constituents such as proteins, carbohydrates, lipids, phospholipids and nucleic acids can be attributed to the enhanced re-synthesis of latex (Low, 1978). Therefore, it is likely that with the higher dosage of ethephon the biosynthesis process upregulated via enhancement of invertase activity, and up - regulated the physiological processes to regenerate cell materials, which had been drained off through tapping, inspite of the nutritional level of the tree.

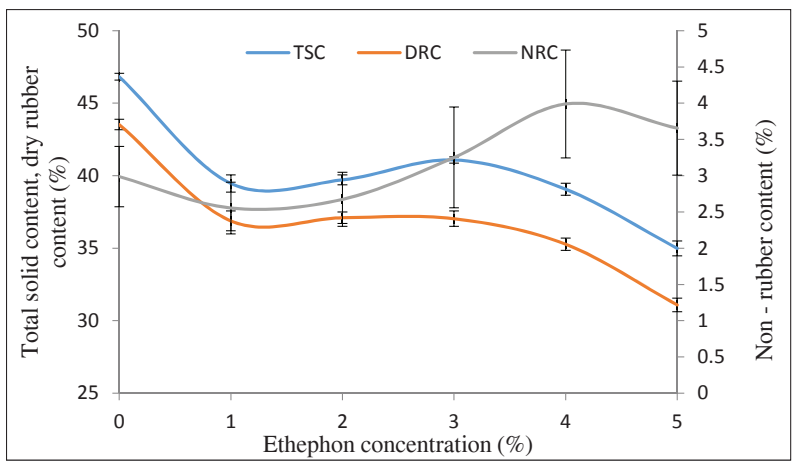

Figure 4: Variation of dry rubber content (DRC), total solid content (TSC) and non-rubber content (NRC) of RRIC 121 genotype harvested under $\mathrm{S} / 2 \mathrm{~d} 3$ system under $1-5 \%$ ethephon concentrations

\section{Volatile fatty acid number}

The volatile fatty acid content in latex increased significantly with ethephon stimulation $(\mathrm{p}<0.001)$. Average volatile fatty acid (VFA) number in unstimulated latex was 0.021 . However with the application of $1-4 \%$ ethephon, VFA number has increased to an average value of 0.028 and it increased significantly up to 0.034 with the application of $5 \%$ ethephon (Figure 2).

Increase of the VFA value can be attributed to achieving optimum condition in latex for bacterial proliferation with more diluted latex with higher percentage of non-rubber constituents. Bacteria preferably grow in more diluted latex rather than highly concentrated latex (Lowe, 1960). It is commonly assumed that VFA originate from sugar degradation and their quantity is indeed one of the most important parameters regarding the quality of latex (Low, 1978; Salomez et al., 2014). Although serum sucrose concentration reduced with the increase of ethephon concentration, an increase 
in VFA value could be observed. Therefore, this can be attributed to the better growth of bacteria in more diluted latex with the supplemented non-rubber medium. High VFA value may contribute to the colloidal de-stability. Therefore, special precautions should be taken for the field level preservation of stimulated latex.

\section{Magnesium content}

Serum magnesium content showed significant variation with ethephon stimulation $(\mathrm{p}<0.001)$. Stimulation with $1 \%$ ethephon lowered serum magnesium content from $183.11 \mathrm{ppm}$ in unstimulated latex to $139.30 \mathrm{ppm}$. Further increase of ethephon dosage from $2-5 \%$ caused further reduction in magnesium content reaching up to $71.50 \mathrm{ppm}$ at $5 \%$ level. However, the observed changes were minimum between $1-3 \%$ ethephon applications (Figure 3). The reduction of serum magnesium content with ethephon treatment have been reported previously (Coupe' \& Chrestin, 1972; da Costa et al., 2005). The reduction in serum magnesium content can be attributed to the enhancement of biosynthesis process as this cation act as a cofactor for several cytosol enzymes; however higher concentration of this cation deactivates the rubber transferase enzyme (da Costa et al., 2005). On the other hand, translocation of this cation to the lutoids provides stability to the latex particles, which are negatively charged. It has been reported that $\mathrm{Mg}^{2+}$ concentration may have some effect on the molecular weight of the rubber formed (Fujii et al., 1980).

\section{Latex rheological behaviour}

Latex viscosity was significantly reduced with ethephon stimulation $(p<0.001)$. With the application of $1 \%$ ethephon, viscosity dropped by $35 \%$ from the value of unstimulated latex. However, with higher ethephon concentrations such as $4 \%$ and $5 \%$, viscosity dropped further by $40-50 \%$, respectively (Figure 5 ). This can be attributed to the reduction in total solid content as well as the changes in molecular weight and molecular weight distribution, branching and chain entanglements. These observations can be explained in terms of Brownian motion. At low shear rates, Brownian motion of the latex particles is predominant and interference between rubber particles is extremely high. As the shear rate increases, rubber particles become deformable and align with the direction of latex flow and exhibit low interference with one another, which results in reduction in viscosity (Bernard \& Richtering, 1995).

When the samples of the present study were tested for viscosity at low shear rates, the behaviour of viscosity was significantly different. The viscosity values were separated into three main groups at low shear rates, and $4 \%$ and $5 \%$ stimulated samples showed higher viscosity at low shear rates than $1-3 \%$ in spite of the lowest total solid content (Figure 6). This erratic variation in viscosity can be explained in terms of non-Newtonian behaviour of natural rubber latex. With increasing ethephon concentration above $3 \%$, most of the nonrubbers come out with latex (Figure 6), which includes lutoid particles. During shearing, lutoid particle breaks similar to the fractionation process and contents come out to the medium. This would cause an increase in viscosity at low shear rates and the resultant effect will diminish with increasing shear rate.

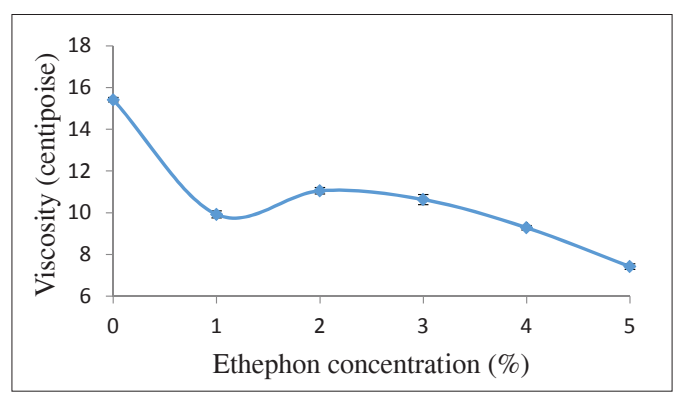

Figure 5: Variation of latex viscosity measured at $30^{\circ} \mathrm{C}$ under shear rate of $60 \mathrm{rpm}$, with the application of $1-5 \%$ ethephon concentration

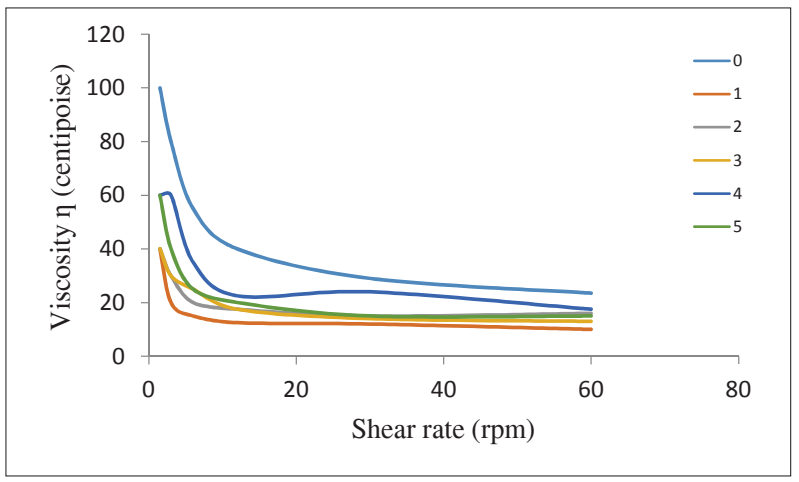

Figure 6: Rheological behaviour of stimulated latex treated with $1-5 \%$ ethephon with different shear rates at $30{ }^{\circ} \mathrm{C}$ (spindle no. 2)

\section{CONCLUSION}

With the increase of ethephon concentration from 1 to $5 \%$, the latex volume, dry rubber yield and thiol content reached a maximum level at $3 \%$, while serum sucrose content showed a minimum. Both TSC and 
DRC significantly reduced with simultaneous increase in non-rubber content and volatile fatty acid content as a result of increased level of ethephon. Enhanced ethephon concentration facilitated the reduction in latex viscosity and the reduction of serum magnesium content enhanced the lutoid stability, which ultimately increases the latex flow time. The results revealed that all the properties studied were significantly affected by ethephon application and a maximum yield with optimum properties could be achieved with the application of $3 \%$ ethephon with $\mathrm{S} / 2 \mathrm{~d} 3$ harvesting system. Application of recommended dosage may only provide the optimum results and excessive use of ethephon may deteriorate the expected results.

\section{REFERENCES}

1. Attanayake A.P. (2016). Study on ethephon stimulation of natural rubber latex on physio-chemical properties of rubber. $P h D$ thesis, University of Sri Jayewardenapura, Sri Lanka.

2. Berend K. \& Richtering W. (1995). Rheology and diffusion of concentrated monodisperse and bidisperse polymer lattices. Journal of Colloids and Surfaces A: Physicochemical and Engineering Aspects 99(2 - 3): $101-119$.

3. Bealing F.J. \& Chua S.E. (1972). Output, composition and metabolic action activity of hevea latex in relation to tapping intensity on the onset of brown bast. Journal of Rubber Research Institute of Malaysia 23: 204.

4. Boyne A.F. \& Ellman G.L. (1972). A methodology for analysis of tissue sulphydryl components. Analytical Biochemistry 46: 639 - 653 .

5. Coupé M. \& Chrestin H. (1972). Physico-chemical and biochemical mechanisms of hormonal (ethylene) stimulation. Physiology of Rubber Tree Latex (eds. J. d' Auzac, J.L. Jacob \& H. Chrestin), pp. 304. CRC Press, Boca Raton, Florida, USA.

6. D'Auzac J. \& Jacob J.L. (1984). Physiology of the laticiferous system Hevea basis and application to productivity. Compte -Rendu du Collogue ExploitationPhysiologic et Amelioration de I'Hevea, July 1984, p. 63, Paris I R C A - GERDAT.

7. D' Auzac J. \& Jacob J.L. (1989). The composition of latex from Hevea brasiliensis as a laticiferous cytoplasm. Physiology of Rubber Tree Latex (eds. J. d'Auzac, J.L. Jacob \& H. Chrestin), pp. 60 - 88. CRC Press, Boca Raton, Florida, USA.

8. da Costa B.M., Keasling J.D. \& Cornish K. (2005). Regulation of rubber biosynthetic rate and molecular weight in Hevea brasiliensis by metal cofactor. Biomacromolecules 6(1): $279-289$.

DOI: https://doi.org/10.1021/bm049606w

9. De Jonge P. (1955). Stimulation of yield in Hevea brasiliensis. III. further observation of the effect of yield stimulation. Journal of Rubber Research Institute of
Malaya 14: 383 - 406.

10. Do Kim T., Sivekumaran S. \& Wong K.C. (1996). Effect of tapping and intensive stimulation on yield, dryness incidence and some physiological latex parameters of clone RRIM 600. Journal of Natural Rubber Research 11(3): $200-214$.

11. Fujii H., Sagami H., Koyama T., Ogura K., Seto S., Baba T. \& Allen C.M. (1980). Variable product specificity of solanesyl pyrophosphate synthetase. Biochemical and Biophysical Research Communications 96: 1648 - 1653.

12. Gener P. \& du Plessix C.J. (1976). Effective use of tapping system and stimulation methods towards rational exploitation of Hevea. Proceedings of the International Rubber Research Conference, Rubber Research Institute of Malaysia, Kuala Lumpur, pp. 384 - 395.

13. ISO 124:2014; Latex, rubber -- Determination of total solids content

14. ISO 126:2005; Natural rubber latex concentrate -Determination of dry rubber content

15. ISO 506:1992; Rubber latex, natural, concentrates -Determination of volatile fatty acid number

16. ISO 1652:2011; Rubber latex -- Determination of apparent viscosity by the Brookfield test method

17. Jacob J.L., Eschbach J.M., Prevot J.C., Rousell D., Lacrotte R., Crestin H. \& D'Auzac J. (1986). Physiological basis for latex diagnosis of the functioning of the laticiferous system in rubber trees. Proceedings of the International Rubber Conference, 21 - 25 October, Kuala Lumpur, Malaysia, pp. $43-68$.

18. Jacob J.L., Prevot J.C. \& Primot L. (1981). La pyruvate kinase du latex d'Hevea brasiliensis. Revue Generale $d u$ Caoutchouc et des Plastiques 612 B9.

19. Jacob J.L., Prevot J.C., Roussel D., Lacrotte R., Serres E., d'Auzac J., Eschbach J.M. \& Omont H. (1989). Yield limiting factors, latex physiological parameters, latex diagnosis and clonal typology. Physiology of Rubber Tree Latex (eds. J. d'Auzac, J.L. Jacob \& H. Chrestin), pp. 345 - 382. CRC Press, Boca Raton, Florida, USA.

20. Low F.C. (1978). Distribution and concentration of major soluble carbohydrates in Hevea latex. The effects of ethephon stimulation and the possible role of these carbohydrates in latex flow. Journal of Rubber Research Institute of Malaysia 26: 21 - 32.

21. Lowe J.S. (1960). Substrate for volatile fatty acids formation in natural rubber latex. Transactions of the Institution of the Rubber Industry 36: $202-210$.

22. Pakianathan S.W. (1977). Some factors affecting yield response to stimulation with 2-chloroethyl-phosphonic acid. Journal of Rubber Research Institute of Malaysia 25: 50 .

23. Rodrigo V.H.L., Kudaligama K.V.V.S., Fernando K.M.E.P. \& Yapa P.A.J. (2012). Replacing traditional half spiral cut by a quarter cut with ethephon; a simple approach to solve current issues related to latex harvesting in rubber industry. Journal of the National Science Foundation of Sri Lanka 40(4): 283 - 291.

DOI: https://doi.org/10.4038/jnsfsr.v40i4.5042 
24. Salomez M., Subileau M., Intapun J., Bonfils F., SainteBeuve., Vaysse L. \& Dubreucq E. (2014). Micro-organisms in latex and natural rubber coagula of Hevea brasiliensis and their impact on rubber composition, structure and properties. Journal of Applied Microbiology 117: 921 - 929. DOI: https://doi.org/10.1111/jam.12556

25. Scott T.A. \& Melvin E.H. (1953). Determination of dextran with anthrone. Analytical Chemistry 25(11): 1656 - 1661. DOI: https://doi.org/10.1021/ac60083a023

26. Tupy J. (1973). Influence of the hormonal stimulation of the production on the sucrose content in the Hevea brasiliensis latex. Revue Générale du Caoutchouc et des Plastiques 50: $311-314$.

27. Van Gils G.E. (1951). Studies of the viscosity of latex $i$ influence of the dry rubber content. Arckf Rubber cult NedIndie 28: 61.

28. Vijayakumar K.R., Thomas K.U., Rajagopal R. \& Karunaichamy K. (2001). Low frequency tapping systems for reduction in cost of production of natural rubber. The Planters' Chronicle 97(11): 451 - 454. 